\title{
Evaluating adaptation options for urban flooding based on new high-end emission scenario regional climate model simulations
}

\author{
K. Arnbjerg-Nielsen ${ }^{1, *}$, L. Leonardsen ${ }^{2}$, H. Madsen ${ }^{3}$ \\ ${ }^{1}$ Department of Environmental Engineering, Technical University of Denmark, Miljovej, Building 113, 2800 Lyngby, Denmark \\ ${ }^{2}$ Copenhagen Municipality, Njalsgade 13, 1505 Copenhagen V, Denmark \\ ${ }^{3}$ DHI, Agern Alle 5, 2970 Hørsholm, Denmark
}

\begin{abstract}
Climate change adaptation studies on urban flooding are often based on a model chain approach from climate forcing scenarios to analysis of adaptation measures. Previous analyses of climate change impacts in Copenhagen, Denmark, were supplemented by 2 high-end scenario simulations. These include a regional climate model projection forced to a global temperature increase of $6^{\circ} \mathrm{C}$ in 2100 as well as a projection based on a high radiative forcing scenario (RCP8.5). With these scenarios, projected impacts of extreme precipitation increase significantly. For extreme sea surges, the impacts do not seem to change substantially compared to currently applied projections. The flood risk (in terms of expected annual damage, EAD) from sea surge is likely to increase by more than 2 orders of magnitude in 2100 compared to the present cost. The risk from pluvial flooding in 2000 is likely to increase by almost 4 and 8 times the current EAD for the RCP8.5 and $6^{\circ} \mathrm{C}$ scenario, respectively. For both hazards, business-as-usual is not a possible scenario, since even in the absence of policy-driven changes, significant autonomous adaptation is likely to occur. Copenhagen has developed an adaptation plan to pluvial flooding that makes the urban areas more robust and reduces the risk of flooding under the current climate to a very low level. The reduction in flood risk for the A1B scenario is substantial (corresponding to $0.2-0.3$ times the current EAD in 2100), and even in the high-end scenarios, the risk is significantly reduced (corresponding to 0.6-1.0 and 1.2-2.1 times the current EAD for the RCP8.5 and $6^{\circ} \mathrm{C}$ scenario, respectively).
\end{abstract}

KEY WORDS: Climate change adaptation · Pluvial flooding $\cdot$ High-end scenarios $\cdot$ Copenhagen · Precipitation $\cdot$ Climatic extremes

\section{INTRODUCTION}

Studies focusing on how to adapt urban areas to increased flood risk from climate change are often based on a model chain approach consisting of the following elements: (1) climate forcing scenarios, (2) global and regional climate model projections, (3) statistical downscaling, (4) hydrological modelling and (5) flood hazard analysis (see e.g. Dankers \& Feyen 2009, Wilby \& Dessai 2010, Madsen et al. 2014). The use of different scenarios, climate projections, downscaling methods and hydrological mod-

\footnotetext{
${ }^{*}$ Corresponding author: karn@env.dtu.dk
}

els may lead to very different results. Thus, it is generally recommended to use several options at the different stages of the model chain, in order to quantify the uncertainty in the impact assessment (Wilby \& Harris 2006, Arnbjerg-Nielsen et al. 2013). Several studies have used an ensemble of projections from global and regional climate models for evaluating changes in flood frequency (see e.g. Veijalainen et al. 2010 or Rojas et al. 2012). Some studies have also included alternative statistical downscaling methods (see e.g. Willems \& Vrac 2011, Sunyer et al. 2012, 2015) or the inclusion of hydro-

() The authors 2015. Open Access under Creative Commons by Attribution Licence. Use, distribution and reproduction are unrestricted. Authors and original publication must be credited. 
logical modelling uncertainty (Lawrence \& Haddeland 2011).

Climate change adaptation in response to increased risk of flooding has been high on the political agenda in a number of countries during recent years, and hence climate change adaptation planning has occurred in a number of cities worldwide, including New York (Rosenzweig et al. 2011) and London (Penning-Rowsell et al. 2013, Ranger et al. 2013). In Denmark, the need for rapid reaction has been further exacerbated by a large increase in the number of extreme precipitation events (Gregersen et al. 2013). These events have resulted in pluvial flooding in most major cities in Denmark during the last $10 \mathrm{yr}$. One of the largest of these storms hit the capital city of Copenhagen on 2 July 2011. During this event, precipitation intensities higher than $2000 \mathrm{yr}$ return periods were recorded at the most critical locations. The damage to the city was substantial; insurance companies reported that $>30 \%$ of building owners in the municipality of Copenhagen filed insurance claims after the event, and the total claims exceeded 800 million euros. The municipality has responded by developing master plans for climate change adaptation and is currently developing more detailed planning for all major urban catchments in the Copenhagen region.

Development of such adaptation studies is based on recommendations of projected changes of climate extremes. Copenhagen Municipality (2011) made an assessment of future impacts on which their climate change adaptation plan is based. Based on this assessment, pluvial flooding and sea surges were selected as key areas where strategic initiatives were needed. An initial screening indicated that from an economic point of view, measures against sea surges should be implemented 30 to 40 yr from now, whereas it was highly advantageous to start implementing adaptation plans immediately, in order to mitigate the impacts of increased pluvial flooding risks. An assessment of all climate change impacts on the water cycle in Denmark confirmed that pluvial flooding is probably the most important factor to consider (Refsgaard et al. 2013).

In this study, we analyse anticipated changes of precipitation extremes and sea surges and their impacts on Copenhagen in a business-as-usual scenario, as well as in a scenario where the Copenhagen adaptation plan against pluvial flooding (the 'cloudburst' plan) is fully implemented. The focus will be on assessing changes in impacts that can be attributed to differences between a moderate climate change scenario such as an A1B scenario (van der Linden \& Mitchell
2009) and high-end scenarios, including a $6^{\circ} \mathrm{C}$ global warming scenario (Christensen et al. 2015, this Special) and the most intense Representative Concentration Pathway (RCP8.5) scenario (Mayer et al. 2015).

\section{DATA AND METHODS}

\subsection{Climate change impact assessment}

Projections of extreme sea surges and extreme precipitation using high-end scenarios were developed for Copenhagen for the year 2100. They were then compared to the projections that the Copenhagen Municipality has developed and used in its planning for adapting to climate change. The aim of this planning was to estimate changes over a $100 \mathrm{yr}$ horizon from 2010 to 2110 according to an A2 scenario (Copenhagen Municipality 2011). Projections of climate change impacts for extreme precipitation were in accordance with national guidelines at the time (Arnbjerg-Nielsen 2012). For sea surges, no national guidelines existed, and hence the municipality derived its own projection.

\subsubsection{Extreme sea surges}

Mean sea level rise and changes in storminess will have an impact on extreme sea surges. Grinsted et al. (2015, this Special) developed probabilistic projections of expected mean sea level rise in northern Europe in the year 2100 based on the RCP8.5 scenario. They estimated a median sea level rise in Copenhagen of $68 \mathrm{~cm}$ and a 5-95\% uncertainty range of $29-162 \mathrm{~cm}$. To estimate the expected changes in sea surges, model simulations have been carried out with a hydrodynamic model covering the North Sea, Baltic Sea and inner Danish waters (M. Rugbjerg \& P. Jensen unpubl.). The model was forced with simulated wind and atmospheric pressure fields for current (using the control period 1961-1990) and future conditions (2071-2100) from 3 regional climate models from the ENSEMBLES data archive (van der Linden \& Mitchell 2009). The results showed an unchanged extreme sea surge signal in 2100 (relative to mean sea level) in the waters around Copenhagen, i.e. only changes in mean sea level contribute to changes in extreme sea surges. The results of the studies are summarised in Table 1 and compared to the expected increases in extreme sea surges used in the climate change adaptation plan developed by the Copenhagen Municipality. 
Table 1. Summary of increases in extreme sea surges $(\mathrm{cm})$ in Copenhagen in 2100 according to the projection used in the Copenhagen climate change adaptation plan (Copenhagen Municipality 2011) and the projection for the RCP8.5 scenario in Grinsted et al. (2015)

\begin{tabular}{|lcc|}
\hline \multirow{2}{*}{ Projection } & \multicolumn{2}{c|}{ Return period } \\
& $10 \mathrm{yr}$ & $100 \mathrm{yr}$ \\
\hline Current planning & 94 & 103 \\
RCP8.5 scenario, median & 68 & 68 \\
RCP8.5 scenario, & 162 & 162 \\
95\% uncertainty quantile & & \\
\hline
\end{tabular}

\subsubsection{Extreme precipitation}

The recommendation regarding the most likely climate change impacts on extreme precipitation in Denmark used by the Copenhagen Municipality is based on Arnbjerg-Nielsen (2012). The recommendation has recently been revised based on an assessment including different climate forcing scenarios, climate model projections and statistical downscaling methods (Gregersen et al. 2014). A key input to the revised recommendation is the use of a multi-model ensemble of regional climate projections in Europe from the ENSEMBLES project (van der Linden \& Mitchell 2009) and application of 3 different downscaling methods (Sunyer et al. 2015). In addition, results based on a high-end scenario are included using a projection of the RCP8.5 scenario (Mayer et al. 2015) downscaled by means of a stochastic weather generator (Sørup et al. 2015). Based on this ensemble of information, 'mean' and 'high' changes are suggested as a function of the projection horizon and return period. Sunyer et al. (2015) showed that, in general, the recommendation given until now is conservative in comparison to the ensemble results using the A1B scenario, but that the RCP8.5 scenario leads to substantially larger changes in extreme precipitation. The new guideline recommends use of 'mean' changes that correspond to the recommendations given so far, but recommends additional analysis to be carried out with a higher change. The changes in extreme precipitation used by the Copenhagen Municipality corresponding to current 'mean' recommendations are summarised in Table 2.

To estimate changes in extreme precipitation based on the $6^{\circ} \mathrm{C}$ scenario simulation, 2 different statistical downscaling methods were applied, viz. a direct change factor methodology and a space-for-time approach, representing 2 very different methods based on extreme and average properties of climate change, respectively. Both methods were also used in the
Table 2. Summary of climate factors (dimensionless) for extreme precipitation. Current planning used by the Copenhagen Municipality is based on Arnbjerg-Nielsen (2012), RCP8.5 according to Sørup et al. (2015) and the estimated climate factors for the $6^{\circ} \mathrm{C}$ scenario

\begin{tabular}{|lcc|}
\hline & \multicolumn{2}{c|}{ Return period } \\
& $10 \mathrm{yr}$ & $100 \mathrm{yr}$ \\
\hline Hourly precipitation & & \\
Current planning & 1.3 & 1.4 \\
RCP8.5 & 1.8 & 2.2 \\
Global 6 ${ }^{\circ} \mathrm{C}$ scenario & 2.2 & 2.7 \\
& & \\
Daily precipitation & & \\
Current planning & 1.3 & 1.4 \\
RCP8.5 & 1.6 & 1.8 \\
Global $6^{\circ} \mathrm{C}$ scenario & 1.5 & 1.7 \\
\hline
\end{tabular}

analysis of the ENSEMBLES data by Sunyer et al. (2015). The methods are briefly outlined below.

The direct change factor approach is based on estimating the changes in extreme precipitation statistics from the regional climate model projections. In this case, climate model simulations are available for the periods 1976-2005 and 2071-2100 (Christensen et al. 2015). For each period, a regional extreme value analysis is applied that includes all land points covering Denmark. The regional model uses a partial duration series (PDS) approach, similar to the method applied in the analysis of Danish rainfall extremes by Madsen et al. (2002).

The PDS model includes precipitation events above a threshold, which in this case is defined as the level that includes on average 3 events $\mathrm{yr}^{-1}$ (i.e. for a $30 \mathrm{yr}$ period, the 90 most extreme events are included in the analysis). A generalized Pareto distribution is fitted to the data using a regional estimated shape parameter, following the regional L-moment approach by Hosking \& Wallis (1997). For each land grid point covering Denmark, extreme precipitation statistics can then be estimated for current (1976-2005) and future (2071-2100) conditions. A climate factor is finally obtained as:

$$
\mathrm{CF}_{T, i}=\frac{\hat{x}_{T, i, p}}{\hat{x}_{T, i, c}}
$$

where $\hat{\boldsymbol{x}}_{T, i, c}$ and $\hat{\boldsymbol{x}}_{T, i, p}$ are the estimated extreme precipitation for a return period of $T$ years in grid point $i$ for current $(c)$ and projected $(p)$, respectively. Climate factors are estimated for both hourly and daily precipitation extremes.

The direct change factor approach focusses specifically on estimating extreme precipitation properties. An alternative method is to search for areas where the 
current climate resembles the projected future climate at the location of interest (often referred to as spacefor-time or climate analogue method). The first application of such an approach within climate change impacts was by Hallegatte et al. (2007). Here we used the method applied by Arnbjerg-Nielsen et al. (2015) for identifying climate analogue regions for Denmark based on the ENSEMBLES A1B scenario simulations. In their study, the following 3 indices were given the highest priority when defining climate analogues: (1) monthly distribution of mean temperature, (2) monthly distribution of mean precipitation and (3) extreme value statistics of daily precipitation.

For the 2 indices based on monthly values, a metric $S_{i}$ is calculated that measures the similarity between the projected future climate at a specified location with the current climate at other locations:

$$
S_{i}=\frac{\sqrt{\sum_{k=1}^{12}\left(x_{C, k, i}-x_{p, k, i}\right)^{2}}}{\sqrt{\sum_{k=1}^{12} x_{p, k, i}{ }^{2}}}
$$

where $x_{c, k, i}$ is the monthly value $(k)$ of index $i$ of the current climate $(c)$, and $x_{p, k, i}$ is the projected $(p)$ monthly value of index $i$ at the specified location. A low value of the metric corresponds to high climatic similarity. Similarly, for the index based on extreme value statistics, the metric is calculated as:

$$
S_{i}=\frac{\sqrt{\sum_{k=1}^{N}\left(x_{C, k, i}-x_{p, k, i}\right)^{2}}}{\sqrt{\sum_{k=1}^{N} x_{p, k, i}^{2}}}
$$

where $N$ is the number of estimated extreme precipitation events for given return periods, $x_{C, k, i}$ is the estimated event of the current climate, and $x_{p, k, i}$ is the projected event at the specified location. In the current setup, $N$ is set to 2 , using 1 and 10 yr return periods. For all 3 metrics, the E-OBS data of daily precipitation and temperature (Haylock et al. 2008) are used to define the current climate throughout Europe.

\subsection{Vulnerability and adaptation assessment}

Vulnerability is measured in monetary terms given that precipitation and sea surge hazards occur in the present climate and in the projected future climate (2100). The costs of flooding are based on assessment of flooded areas for a range of return periods and for each return period registering a unit cost of flooding for the following types of assets: repair costs of flooded basements, houses, businesses (including inventory replacement) and infrastructure, as well as costs due to disruption of traffic and electricity. These calculations are summarised by COWI (2010). The costs for different return periods are then converted into an annual risk for the area in question by calculating the expected annual damage (EAD), i.e. the damage that on average will occur due to flooding. Here, $p$ denotes the inverse of the return period, i.e. the probability of such an event occurring in any given year. The EAD is then calculated as (Olsen et al. 2015):

$$
\mathrm{EAD}=\int_{0}^{1} D(p) d p
$$

where $D(p)$ is the cost at probability $p$. It is assumed that no damage occurs for return periods below $1 \mathrm{yr}$. Olsen et al. (2015) provided details of various ways of solving this integral.

The analysis of present flood risk indicated that flood damage already starts to occur at return periods below the design criteria (typically $10 \mathrm{yr}$ ). This is in accordance with other case studies and most likely because city development sometimes occurs without taking flood risk into account (see e.g. Ward et al. 2011, Zhou et al. 2012a, Olsen et al. 2015). It is therefore assumed that future adaptation scenarios also will entail small flood damages at return periods below the design level.

The Copenhagen Municipality has developed its adaptation plan under the assumption that the urban

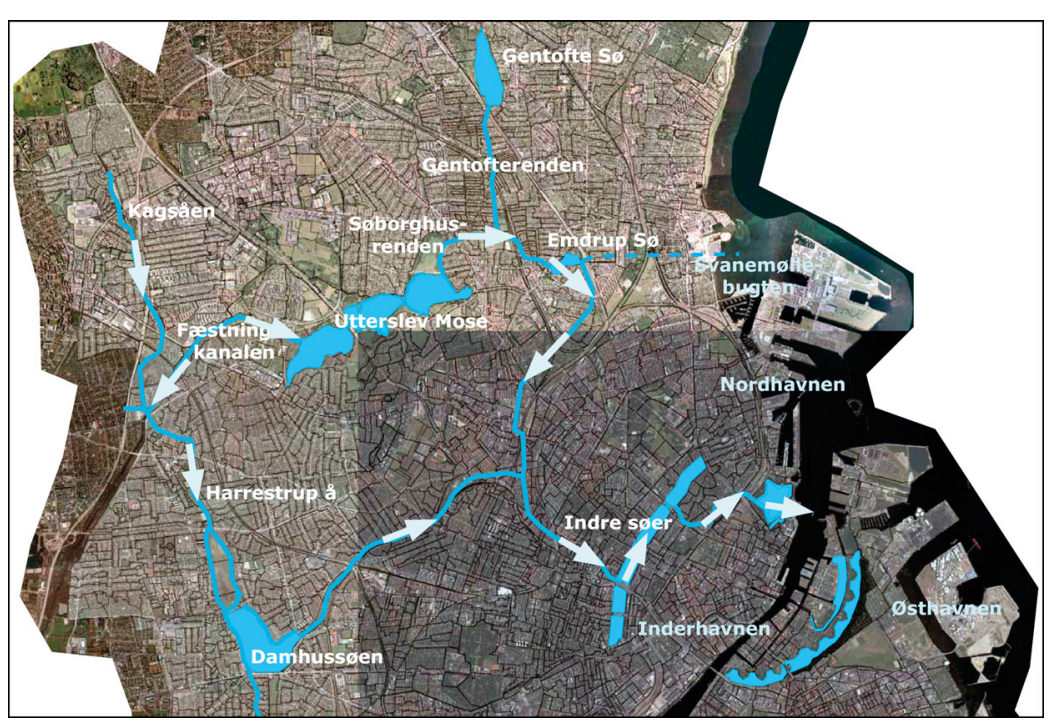

Fig. 1. Overview of surface waters and conveyance routes in Copenhagen, Denmark. The map covers an area of $10 \times 12 \mathrm{~km}$ 
fabric should change as little as possible. This implies that none of the affected assets (houses, businesses etc.) are moved per se, but instead the adaptation measures increase the return period at which damage will occur. This is in accordance with similar studies (see e.g. Zhou et al. 2012b). In cases where the adaptation measures are based on retaining water in depressions within the catchment, this may be an optimistic assessment, because once the depression is filled, the efficiency of the measure is reduced. In order to compensate for this process, it is assumed that the cost of exceeding the volumetric capacity of the depression varies between 0 and half the cost of not implementing the measure at all.

Using these assumptions, relative EAD was calculated for both precipitation and sea surge hazards under a business-as-usual scenario and for precipitation hazards assuming that the cloudburst adaptation plan is fully implemented. For the purposes of this study, the EAD calculations of the adaptation plan were adjusted to cover the period 2000-2100 to align the projection periods.

\section{CURRENT COPENHAGEN CLIMATE CHANGE ADAPTATION PLAN FOR PROJECTED INCREASES IN PRECIPITATION EXTREMES}

Copenhagen does not have large natural rivers or lakes. An overview of the main surface waters and conveyance routes is given in Fig. 1. The 5 surface waters (Damhussøen and Indre søer) in the region were all constructed during the 18th century as part of a system of defence structures against military attacks on the city, and the natural rivers have very low flow due to very low groundwater levels. Because of the low natural water flow, the rivers are piped, and from a legal point of view they are considered an integral part of the urban drainage system.

Based on an initial screening on the city-level of anticipated current (2010) and future (2110) costs of damage caused by precipitation extremes, the following were concluded in Copenhagen Municipality (2011):

- Currently, the expected annual cost of flooding due to precipitation extremes exceeds $€ 1000$ person $^{-1} \mathrm{yr}^{-1}$.

- In the old parts of the city, buildings with basements are predominant. The value-at-risk in relation to these basements is high, and suitable measures to protect these are difficult to identify if executed by the municipality and/or the utility.

- If an optimal combination of surface and subsurface adaptation measures were implemented, even a very substantial reduction in risk would have a positive net present value. Under some very crude assumptions, the highest net present value was found to be around a $90 \%$ reduction of current costs of flooding. A major assumption is that urban storm water (and potentially sewage) running on city surfaces have no cost, enabling a substantial saving because some pipes may not need to be resized even though they cannot comply with current requirements of hydraulic capacity.

The main objectives to be met with the climate change adaptation plan towards precipitation extremes were then set as follows:

- All basements should be disconnected from the public sewer system and/or private non-return valves installed to ensure that basements cannot be flooded by sub-surface flows.

- City planning or local initiatives will ensure that up to $10 \mathrm{~cm}$ of water can run on streets and other surfaces without damaging the urban fabric.

- In general, a level of $10 \mathrm{~cm}$ of water on streets must not occur more frequently than 1 in 100 yr in 2110 given current anticipated climate change impacts (corresponding to a current 420 yr return period, see Fig. 6). Roads where this objective cannot be met will be managed by means of contingency measures as well as compensation schemes to affected citizens. These measures are not yet defined, but will be specified as the adaptation plan is developed further in collaboration with regional and national emergency management agencies.

Based on these criteria, 'cloudburst adaptation plans' have been developed for each urban hydrological catchment. An example is shown in Fig. 2. Great care has been taken to ensure that the existing urban fabric can be retained, both in terms of buildings and existing main corridors of transportation. A combination of retaining storm water in most parts of the city has been combined with storage by means of lowering the water level in a lake as well as conveyance corridors (i.e. roads) to a central tunnel that downstream will have a capacity of $27.1 \mathrm{~m}^{3} \mathrm{~s}^{-1}$.

\section{RESULTS}

\subsection{Climate change impact assessment}

Considering the projected changes in extreme sea surges used by the Copenhagen Municipality and the changes projected by the A2 scenario (Table 1), it is more than likely that the adaptation plan also accounts for the impact of the RCP8.5 scenario. 


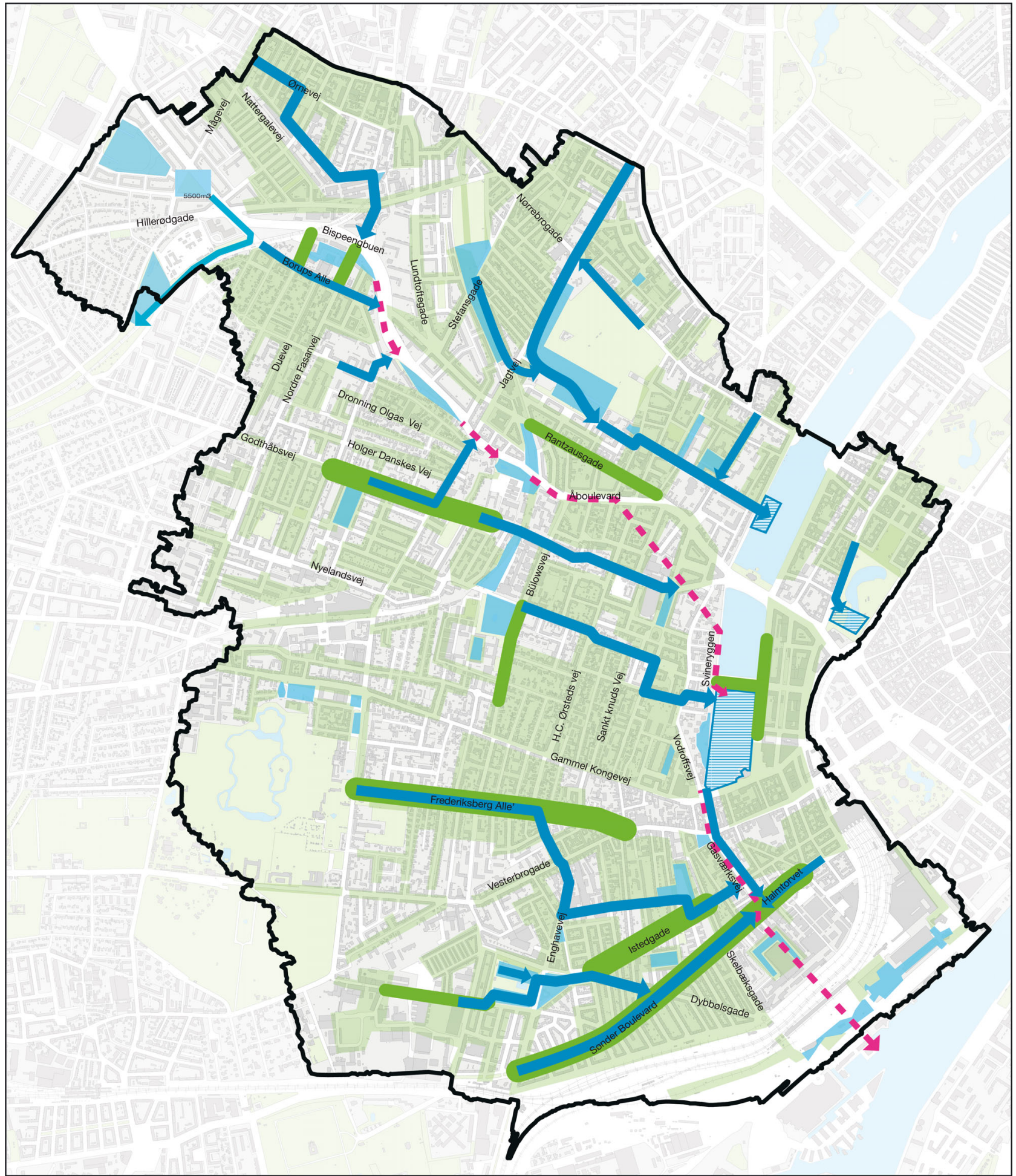

Fig. 2. Overview of adaptation measures planned for 1 urban catchment in Copenhagen $\left(10.8 \mathrm{~km}^{2}\right.$, corresponding to $\sim 20 \%$ of the city's area). Local retention measures are implemented in all areas marked in light green, all roads marked with dark blue indicate that the service level of $10 \mathrm{~cm}$ of water must be managed by local measures (e.g. channels), and mid-blue areas show locations where water will be stored temporarily during major storms. Dark green roads indicate where traffic will be affected because of retention measures implemented on the road itself. Blue hatched areas indicate where water levels will be lowered permanently to allow storage of storm water during heavy storms. A tunnel (dashed red line) with a downstream capacity of $27.1 \mathrm{~m}^{3} \mathrm{~s}^{-1}$ must still be constructed to ensure that the design criterion is achieved 
Therefore, the measures to be implemented for this hazard seem to be sufficient in the currently developed planning, and no further costs are foreseen under the high emission scenarios when considering this hazard alone.

For precipitation, the estimated climate factors for the $6^{\circ} \mathrm{C}$ scenario for different return periods based on the direct change factor method are shown in Fig. 3. The figure shows the average climate factor and the corresponding 16-84\% variability (68\% coverage interval) over the land points covering Denmark.

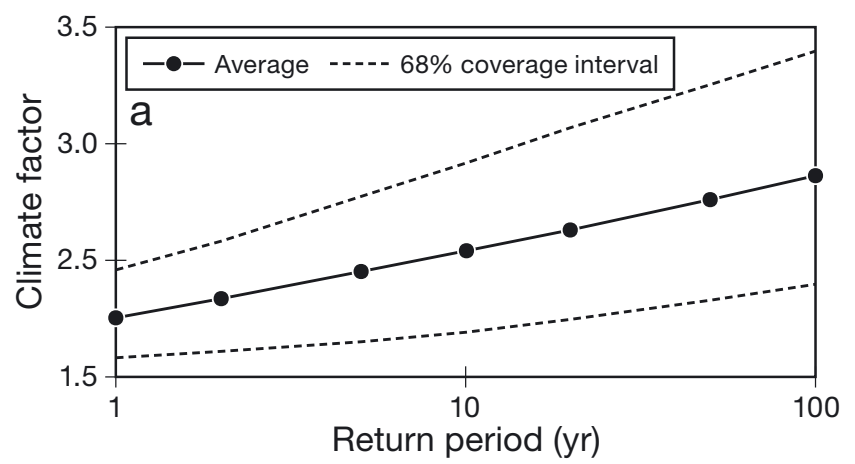

The seasonal distribution of extreme precipitation events for current and future conditions in the $6^{\circ} \mathrm{C}$ scenario is shown in Fig. 4. The frequency of precipitation extremes shows a shift towards more events in autumn and winter. The average magnitude of the extreme events increases in all seasons. These changes could likely have an impact on the occurrence of concurrent events of extreme precipitation and sea surges.

The results of the climate analogue metrics for the $6^{\circ} \mathrm{C}$ scenario are shown in Fig. 5. When calculating

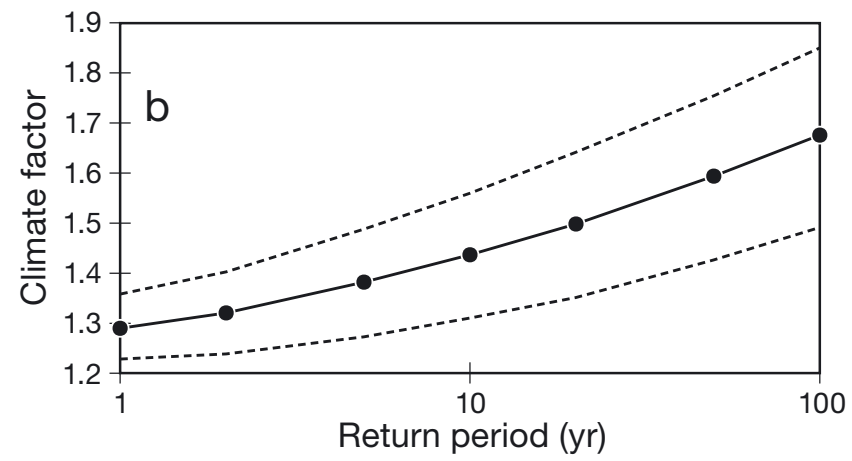

Fig. 3. Calculated climate factors for Denmark for the global $6^{\circ} \mathrm{C}$ scenario as a function of return period for (a) hourly and (b) daily precipitation extremes
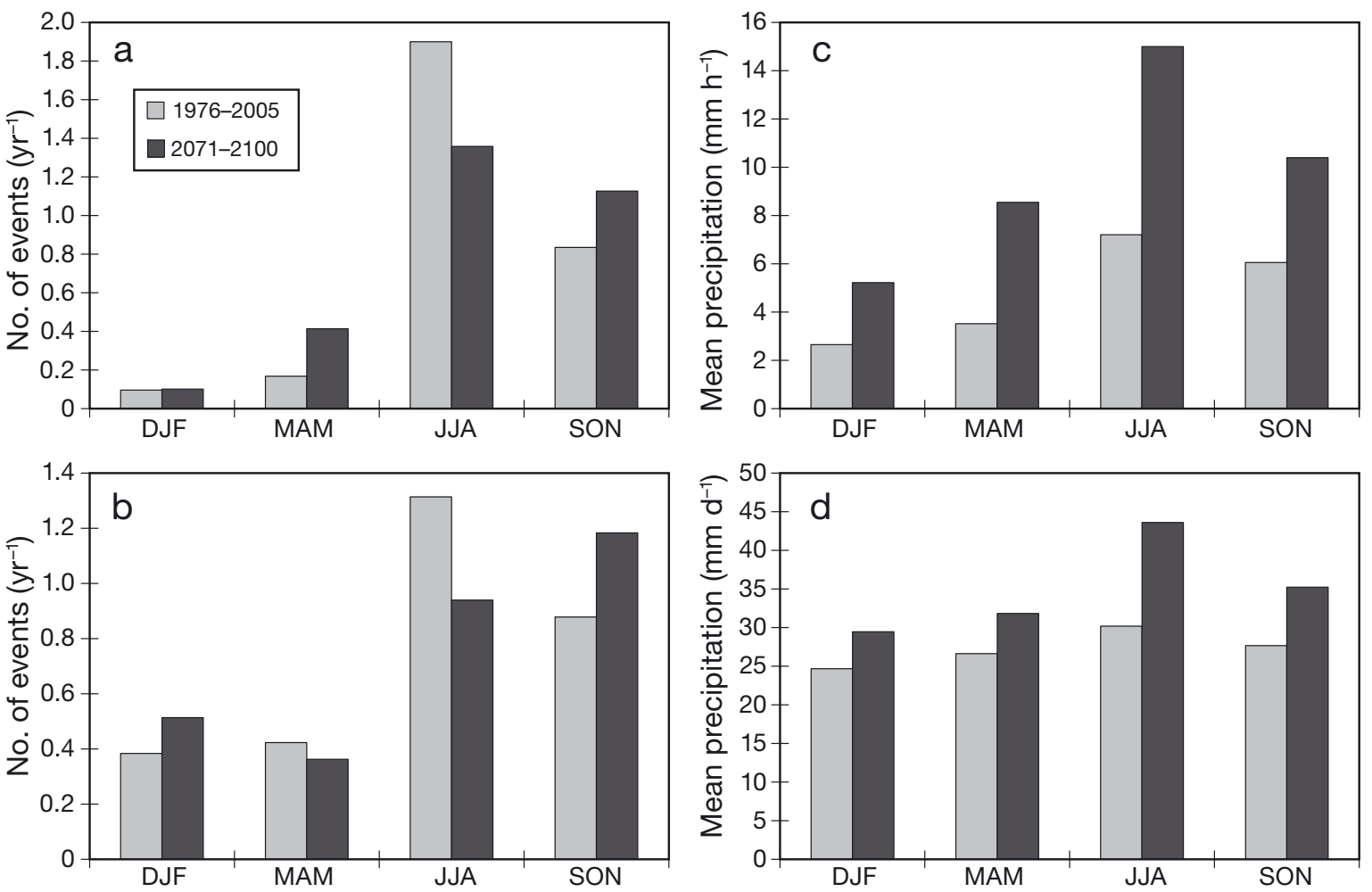

Fig. 4. Seasonal distribution in the $(\mathrm{a}, \mathrm{b})$ number of extreme events and $(\mathrm{c}, \mathrm{d})$ mean event magnitude for $(\mathrm{a}, \mathrm{c})$ hourly and $(\mathrm{b}, \mathrm{d})$ daily precipitation extremes for the $6^{\circ} \mathrm{C}$ scenario 
these metrics for the ENSEMBLES A1B multi-model simulations, analogue locations with a current climate that correspond to a future climate in Denmark are centred around the coastal area of northern France (Arnbjerg-Nielsen et al. 2015). However, in the $6^{\circ} \mathrm{C}$ scenario simulation, each metric has a unique pattern, and combining them to define analogue locations seems difficult (see Fig. 5). The mean
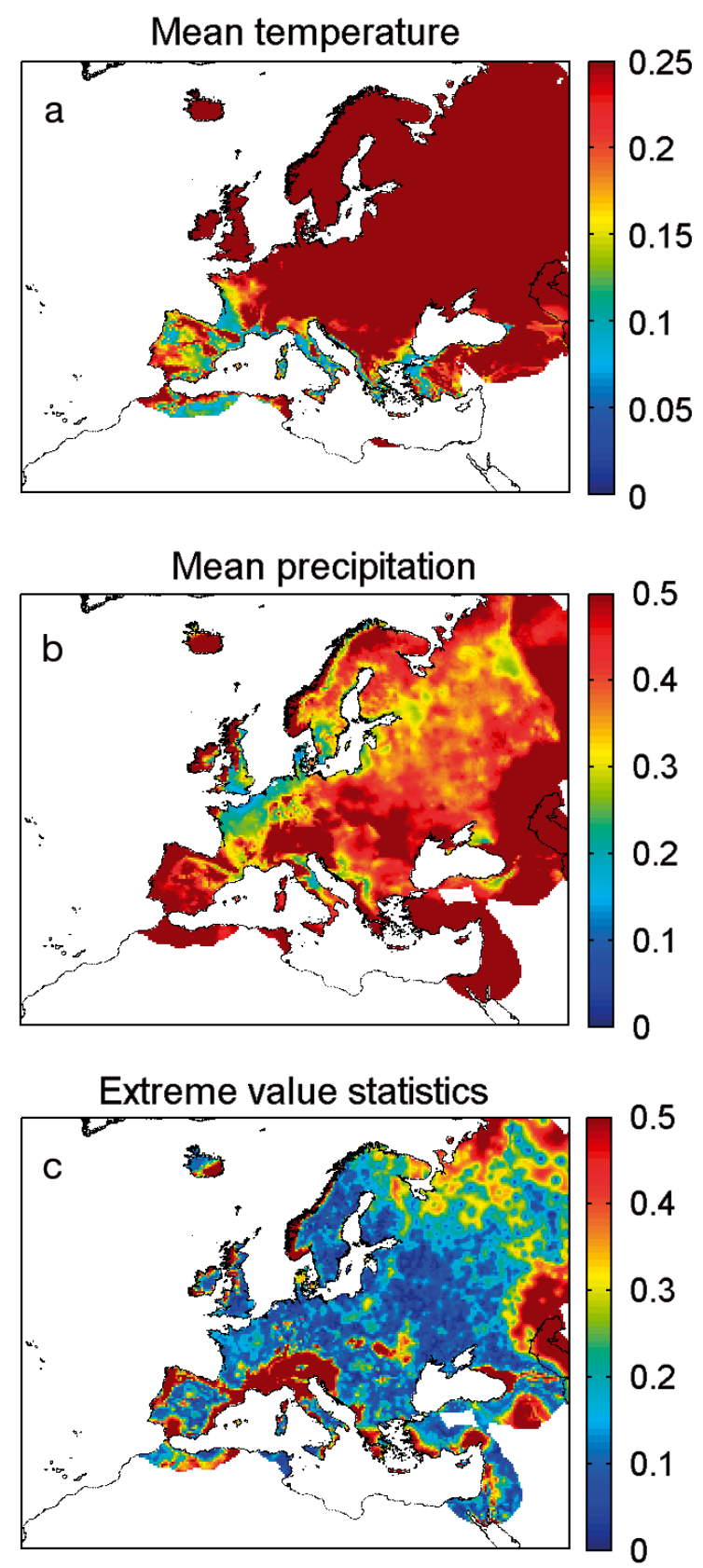

Fig. 5. Calculated space-for-time metrics for the $6^{\circ} \mathrm{C}$ scenario for locations within Europe for (a) mean temperature, (b) mean precipitation and (c) extreme precipitation. Low values of the metrics correspond to high climatic similarity temperature metric points towards locations in coastal southern Europe, the mean precipitation metric points towards locations in the coastal region around the British Channel, the North Sea and the Baltic Sea, and the metric on precipitation extremes varies widely, but mainly identifies locations away from the coastal regions, i.e. in central Europe, Sweden and the parts of southern Europe where the other 2 metrics indicate low climatic similarity. In conclusion, it is difficult to identify a location within Europe where the current climate resembles the future climate in Denmark based on the $6^{\circ} \mathrm{C}$ scenario simulation. Therefore, the results of the direct change factor method were used in the vulnerability and adaptation assessment.

The estimated climate factors are summarised in Table 2, and the corresponding changes in hazard for hourly precipitation extremes are shown in Fig. 6. For the $6^{\circ} \mathrm{C}$ scenario, the change in hazard is more than an order of magnitude. Severe storms with intensities corresponding to what was observed during the event in Copenhagen on 2 July 2011 could occur approximately every 40 yr in 2100 according to this scenario.

\subsection{Vulnerability and adaptation assessment}

The projected vulnerabilities for the business-asusual scenario are shown in Fig. 7. These vulnerabilities are used to calculate relative EADs for precipita-

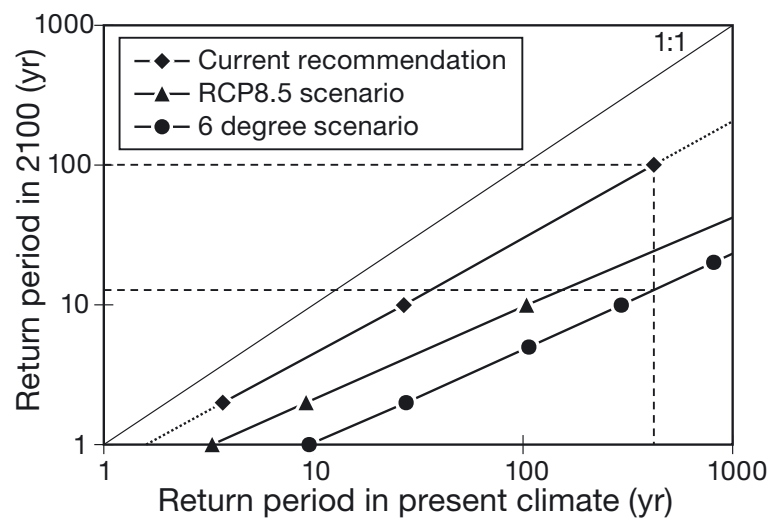

Fig. 6. Change in return periods in hourly extreme precipitation for Copenhagen from present to future for the current planning scenario and the 2 high-end scenarios. Current recommendation only covers return periods between 2 and 100 yr. Extrapolation of this recommendation is indicated by dotted lines. Dashed lines indicate the design criteria of the Copenhagen climate change adaptation plan. For the $6^{\circ} \mathrm{C}$ scenario, this level corresponds to a return period close to $14 \mathrm{yr}$ as opposed to a $100 \mathrm{yr}$ return period anticipated in the adaptation plan 


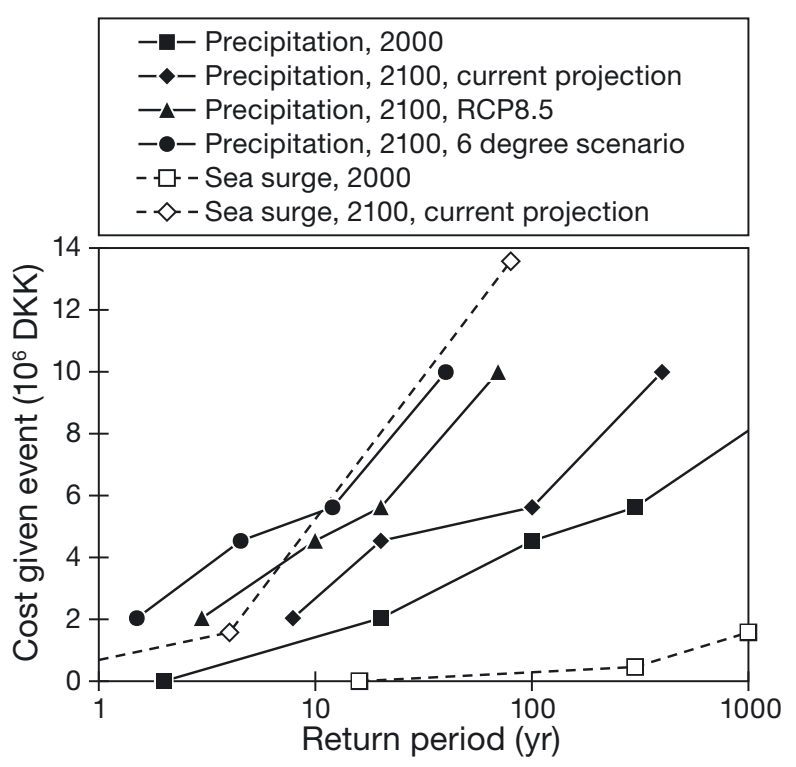

Fig. 7. Vulnerability assessment for precipitation and sea surge hazards. Costs of flooding in present and future (2100) climate under the A2 scenario used during development of the Copenhagen adaptation plan are derived from COWI (2010). The curves for precipitation hazards for 2100 for the RCP8.5 and $6{ }^{\circ} \mathrm{C}$ scenario are calculated based on the assumptions described in Section 2.2. 1 DKK (Danish krone) is approximately 0.13 euro at time of writing

tion and sea surge hazards under a business-as-usual scenario and for a scenario of full implementation of the cloudburst adaptation plan (Table 3).

Based on the A2 scenario projection used by the Copenhagen Municipality, the largest change in risk is expected to be due to sea surges. The EAD increases by more than 2 orders of magnitude, from

Table 3. Calculated expected annual damage (EAD) based on the cost curves shown in Fig. 7. The uncertainty of these estimates is high, and hence relative values are reported, setting current costs of precipitation to an index value of 1

\begin{tabular}{|lc|}
\hline & EAD \\
\hline Precipitation, business-as-usual scenario & \\
Present & 1.0 \\
2100, current projection & 1.7 \\
2100, RCP8.5 & 3.7 \\
2100, $6^{\circ} \mathrm{C}$ scenario & 7.7 \\
Precipitation, cloudburst adaptation plan fully implemented & \\
Present & 0.1 \\
2100, current projection & $0.2-0.3$ \\
2100, RCP8.5 & $0.6-1.0$ \\
$2100,6^{\circ} \mathrm{C}$ scenario & $1.2-2.1$ \\
Sea surge, business-as-usual scenario & $\ll 0.1$ \\
Present & 6.6 \\
2100, current projection & \\
\hline
\end{tabular}

very low values to almost 7 times current annual costs of precipitation extremes. However, for the $6^{\circ} \mathrm{C}$ scenario, the increase in risk for precipitation is very high, and although the relative change in risk is smaller than for sea surges, the EAD for extreme precipitation exceeds the EAD anticipated for sea surges. It is also noteworthy that current adaptation planning is quite efficient even under a $6^{\circ} \mathrm{C}$ scenario, because a high design criterion has been chosen (100 yr return period for flooding) compared to current design standards (10 yr return period). The EAD will be higher than today, and, most importantly, it will be based on fewer and larger events.

\section{DISCUSSION}

The purpose of the discussions below is not aimed at constructing a climate change adaptation plan that complies with the design criteria in a $6^{\circ} \mathrm{C}$ scenario, but rather to discuss what assumptions in the current planning scheme are challenged if the $6^{\circ} \mathrm{C}$ scenario should be taken into account.

\subsection{Limits to making marginal analyses}

The vulnerabilities given the changes in hazards due to climate change impacts are shown in Fig. 7. They are calculated under the assumption that no adaptation will occur and that the city fabric will not change in the future. The main costs are repair costs of buildings and replacement costs of stock and inventory in businesses and stores. As indicated by Figs. $6 \& 7$, the frequency of flooding in the $6^{\circ} \mathrm{C}$ scenario is likely to increase by more than an order of magnitude, implying that some basements could be flooded several times per year, and even the ground floor in some buildings could be flooded with a frequency of $1 \mathrm{yr}$. This implicitly means that business-as-usual is not an option, as the use of these buildings will change as flooding becomes too frequent to allow insuring the assets or even allowing physical repairs to occur between flood events. Hence, a marginal analysis assuming a strategy of business-as-usual is not feasible, because substantial autonomous adaptation will take place. In a businessas-usual scenario, the main subway line connecting northern parts of Copenhagen with the central and southern parts of the 
city is also projected to be flooded at several train stations with a return period below $10 \mathrm{yr}$ in the $6^{\circ} \mathrm{C}$ scenario. It is unlikely that the citizens will allow such frequent disruptions of critical infrastructure.

\subsection{Water infrastructure design considerations recognizing the impacts corresponding to a $6^{\circ} \mathrm{C}$ scenario}

The tradition within design of large infrastructure has been to ensure that the performance of the structure is satisfactory until the end of the technical lifetime of key components. This has led to very long design lifetimes of such systems, typically with mean expected lifetimes exceeding 100 yr (e.g. Larsen et al. 2003, Zhou et al. 2012b). Similar considerations have also been the basis for the current recommendations regarding climate change adaptation for urban drainage systems in Denmark, as briefly outlined in Section 2.1.2.

This paradigm is challenged by some researchers, arguing that the large uncertainties in relation to climate change impacts call for smaller, incremental investments that are cheaper because they are more flexible and lock-in situations are avoided (Gersonius et al. 2013). On the other hand, this practice sometimes leads to sub-optimal solutions, known as the 'tyranny of incremental decisions' (Kahn 1966). Still, the massive changes needed in the urban fabric to accommodate a city that is robust in a $6^{\circ} \mathrm{C}$ scenario probably would lead to some sort of incremental investments, where changes over a shorter time span are considered.

The adaptation plan developed by Copenhagen is more ambitious than needed according to the current design guidelines. Large technical problems prevail, notably on how to technically allow $10 \mathrm{~cm}$ of water to run on most streets without damaging properties or increasing human exposure to pathogens. The choice between increasing storage and increasing conveyance of extreme water flows is also critical, and that choice is particularly sensitive to the actual climate change impact. The choice has been to retain as much water as can be achieved by using all available spaces on which there are no buildings, i.e. parks, parking lots, squares and even heavy modifications of a lake. The needed conveyance in the form of tunnels and channels has been designed to be able to hydraulically convey the excess water. The capacity of all of these planned facilities could, however, be exceeded on average every $14 \mathrm{yr}$ under the $6^{\circ} \mathrm{C}$ scenario (see Fig. 6), leading to uncontrolled flooding of the city. This appears to be a very high frequency, and the current adaptation plan also aims at reducing the frequency of such events (implementing a $100 \mathrm{yr}$ return period for flooding). In any case, it would be advantageous to consider how to manage the residual risk by means of contingency measures, informing and educating the public, restricting spatial planning and considering measures aimed at increasing resilience in the region.

\subsection{Concurrent events}

The cost of an extreme precipitation event will be exacerbated if the sea level is high at the same time. Pedersen et al. (2012) showed that an important climate change impact may be a higher probability of such concurrent extreme events because of a shift in the seasonal pattern of precipitation extremes. The $6^{\circ} \mathrm{C}$ scenario simulation shows that the seasonal pattern of occurrence of precipitation extremes shifts towards more extreme events in autumn and winter and the mean magnitude of the extremes increases substantially (Fig. 4). Hence, since extreme storm surges primarily occur in autumn and winter, the probability of concurrent events is likely to increase, although it is difficult to quantify how much. However, this underpins the importance of developing adaptation plans that are robust to concurrent events, since the costs of climate change will otherwise be underestimated.

\subsection{Practical aspects of implementing climate change adaptation}

The current adaptation plan will change the urban layout in more than half of the total area of the city by changing the city layout to either store higher water volumes or convey water faster. Many of the adaptation measures are believed to improve the livability of the local neighbourhoods by increasing the visibility of water in the city. Still many of the measures are novel and remain to be tested in a setting where water scarcity is not an issue. Also, the concept of allowing $10 \mathrm{~cm}$ of water to flow on most streets without causing damage is challenging because of other critical functions of the city, notably ease-of-access for disabled people and flow of traffic.

The amount of disturbance to the everyday functions of the city when executing the climate change adaptation plan is also a challenge. Currently, a new metro is being built, and the disturbance to 
residential areas and traffic leads to much debate. The tunnel shown in Fig. 2 does not need to be as large as a full metro-tunnel; however, the downstream capacity exceeds by far what can be conveyed in a traditional sewer pipe, and thus tunnelling is likely needed. It remains to be seen how the public will react to disturbances from construction solely for the purpose of management of precipitation extremes. A concrete measure could be to identify and monitor indicators of progress in terms of the implementation of the climate change adaptation plan and the corresponding benefits to ensure that the objectives of the adaptation plan are retained during implementation.

\section{CONCLUSION}

Using an ensemble projection of the effects of climate change on extreme precipitation based mainly on the A1B scenario points towards moderate impacts on pluvial flooding in urban areas in Denmark, whereas using the results from 2 high-end scenarios, the impacts are projected to be much larger. In the $6^{\circ} \mathrm{C}$ scenario, business-as-usual is not an option, since even in the absence of policy-driven adaptation, large-scale autonomous adaptation will occur. Essentially, the most vulnerable urban areas could be abandoned under such a scenario because of damage to assets in these areas that is too frequent and too extensive. In this sense, adaptation implicitly has a 'tipping point' (Kwadijk et al. 2010) between a moderate and a high-end scenario.

We found that for sea surges, the corresponding 'adaptation tipping point' is below current projections, and hence even in a moderate scenario, major adaptation based on policy-driven responses is needed. After a major storm in July 2011, a very ambitious climate change adaptation plan was developed for urban pluvial flooding. If the plan is fully implemented, the Copenhagen region will be well protected even in a high-end scenario. It will take several decades to implement the plan even under the most optimistic circumstances, and it remains to be seen whether the political awareness will remain high if the frequency of extreme precipitation becomes relatively low at some future point in time.

Acknowledgements. This work was carried out with the support of the Danish Council for Strategic Research as part of the projects 'Centre for Regional Change in the Earth System', contract no. 09-066868 and 'Risk Based Design in a Changing Climate (RiskChange)', contract no. 0603-00390B.

\section{LITERATURE CITED}

Arnbjerg-Nielsen K (2012) Quantification of climate change effects on extreme precipitation used for high resolution hydrologic design. Urban Water J 9:57-65

Arnbjerg-Nielsen K, Willems P, Olsson J, Beecham S and others (2013) Impacts of climate change on rainfall extremes and urban drainage systems: a review. Water Sci Technol 68:16-28

> Arnbjerg-Nielsen K, Funder SG, Madsen H (2015) Identifying climate analogues for precipitation extremes for Denmark based on RCM simulations from the ENSEMBLES database. Water Sci Technol 71:418-425

Christensen OB, Yang S, Boberg F, Fox Maule C and others (2015) Scalability of regional climate change in Europe for high-end scenarios. Clim Res 64:25-38

Copenhagen Municipality (2011) Københavns Klimatilpasningsplan (Copenhagen climate change adaptation plan). Copenhagen Municipality, Copenhagen. Available at http://kk.sites.itera.dk/apps/kk_pub2/pdf/1270_ UEsoeIrcLC.pdf (accessed 29 May 2015)

COWI (2010) Muligheder og konsekvenser af klimasikring af København mod oversvømmelser (Possibilities and consequences of climate change adaptation of Copenhagen in relation to flooding). Report to the Copenhagen Municipality, October 2010. COWI, Lyngby

Dankers R, Feyen L (2009) Flood hazard in Europe in an ensemble of regional climate scenarios. J Geophys Res 114:D16108, doi:10.1029/2008JD011523

Gersonius B, Ashley R, Pathirana A, Zevenbergen C (2013) Climate change uncertainty: building flexibility into water and flood risk infrastructure. Clim Change 116: 411-423

Gregersen IB, Madsen H, Rosbjerg D, Arnbjerg-Nielsen K (2013) A spatial and nonstationary model for the frequency of extreme rainfall events. Water Resour Res 49: $127-136$

Gregersen IB, Madsen H, Linde JJ, Arnbjerg-Nielsen K (2014) Opdaterede klimafaktorer og dimensionsgivende regnintensiteter (Updated climate change factors and extreme precipitation used for design intensities). Paper no. 30. The Water Pollution Committee of The Society of Danish Engineers. Available at https://ida.dk/sites/prod. ida.dk/files/svk_skrift30_0.pdf (accessed January 2015)

Grinsted A, Jevrejeva S, Riva REM, Dahl-Jensen D (2015) Sea level rise projections for northern Europe under RCP8.5. Clim Res 64:15-23

> Hallegatte S, Hourcade JC, Ambrosi P (2007) Using climate analogues for assessing climate change economic impacts in urban areas. Clim Change 82:47-60

> Haylock MR, Hofstra N, Klein Tank MG, Klok EJ, Jones PD, New M (2008) A European daily high-resolution gridded data set of surface temperature and precipitation for 1950-2006. J Geophys Res 113:D20119, doi:10.1029/ 2008JD010201

Hosking JRM, Wallis JR (1997) Regional frequency analysis: an approach based on L-moments. Cambridge University Press, New York, NY

Kahn AE (1966) The tyranny of small decisions: market failures, imperfections, and the limits of economics. Kyklos 19:23-47

Kwadijk JCJ, Haasnoot M, Mulder JPM, Hoogvliet MMC and others (2010) Using adaptation tipping points to prepare for climate change and sea level rise: a case study in the Netherlands. WIREs Clim Change 1:729-740 
Larsen OD, Moelgaard C, Kampmann J (2003) Flooding of the Copenhagen Metro, Denmark. Struct Eng Int 13: 231-234

Lawrence D, Haddeland I (2011) Uncertainty in hydrological modelling of climate change impacts in four Norwegian catchments. Hydrol Res 42:457-471

Madsen H, Mikkelsen PS, Rosbjerg D, Harremoës P (2002) Regional estimation of rainfall intensity-duration-frequency curves using generalized least squares regression of partial duration series statistics. Water Resour Res 38:1239, doi: 10.1029/2001WR001125

Madsen H, Lawrence D, Lang M, Martinkova M, Kjeldsen TR (2014) Review of trend analysis and climate change projections of extreme precipitations and floods in Europe. J Hydrol (Amst) 519:3634-3650

Mayer S, Fox Maule C, Sobolowski S, Christensen OB and others (2015) Identifying added value in high-resolution climate simulations over Scandinavia. Tellus Ser A Dyn Meterol Oceanogr 67:24941

Olsen AS, Zhou Q, Linde JL, Arnbjerg-Nielsen K (2015) Comparing methods of calculating expected annual damage in urban pluvial flood risk assessments. Water 7: 255-270

Pedersen AN, Mikkelsen PS, Arnbjerg-Nielsen K (2012) Climate change-induced impacts on urban flood risk influenced by concurrent hazards. J Flood Risk Manag 5: 203-214

Penning-Rowsell EC, Haigh N, Lavery S, McFadden L (2013) A threatened world city: the benefits of protecting London from the sea. Nat Hazards 66:1383-1404

Ranger N, Reeder T, Lowe J (2013) Addressing 'deep' uncertainty over long-term climate in major infrastructure projects: four innovations of the Thames Estuary 2100 Project. EURO J Decis Process 1:233-262

Refsgaard JC, Arnbjerg-Nielsen K, Drews M, Halsnæs K and others (2013) The role of uncertainty in climate change adaptation strategies - a Danish water management example. Mitig Adapt Strategies Glob Change 18: 337-359

Rojas R, Feyen L, Bianchi A, Dosio A (2012) Assessment of future flood hazard in Europe using a large ensemble of bias-corrected regional climate simulations. J Geophys Res Atmos 117:D17109, doi:10.1029/2012JD017461

Rosenzweig C, Solecki WD, Blake R, Bowman M and others (2011) Developing coastal adaptation to climate change

Submitted: May 5, 2014; Accepted: March 24, 2015 in the New York City infrastructure-shed: process, approach, tools, and strategies. Clim Change 106:93-127

Sørup HJD, Christensen OB, Arnbjerg-Nielsen K, Mikkelsen PS (2015) Downscaling future precipitation extremes to urban scales using a spatio-temporal Neyman-Scott weather generator. Hydrol Earth Syst Sci Discuss 12: 2561-2605

Sunyer M, Madsen H, Ang PH (2012) A comparison of different regional climate models and statistical downscaling methods for extreme rainfall estimation under climate change. Atmos Res 103:119-128

Sunyer MA, Gregersen IB, Madsen H, Rosbjerg D, ArnbjergNielsen K (2015) Comparison of different statistical downscaling methods to estimate changes in hourly extreme precipitation using RCM projections from ENSEMBLES. Int J Climatol (in press) doi:10.1002/joc.4138

van der Linden P, Mitchell JFB (eds) (2009) ENSEMBLES: Climate change and its impacts. Summary of research and results from the ENSEMBLES project. Met Office Hadley Centre, Exeter. Available at http://ensembles-eu. metoffice.com/docs/Ensembles_final_report_Nov09.pdf (accessed February 2015)

> Veijalainen N, Lotsari E, Alho P, Vehviläinen B, Käyhkö J (2010) National scale assessment of climate change impacts on flooding in Finland. J Hydrol (Amst) 391:333-350

Ward PJ, de Moel H, Aerts JCJH (2011) How are flood risk estimates affected by the choice of return-periods? Nat Hazards Earth Syst Sci 11:3181-3195

Wilby RL, Dessai S (2010) Robust adaptation to climate change. Weather 65:180-185

Wilby RL, Harris I (2006) A framework for assessing uncertainties in climate change impacts: low-flow scenarios for the River Thames, UK. Water Resour Res 42:W02419, doi: 10.1029/2005WR004065

Willems P, Vrac M (2011) Statistical precipitation downscaling for small-scale hydrological impact investigations of climate change. J Hydrol (Amst) 402:193-205

> Zhou Q, Halsnæs K, Arnbjerg-Nielsen K (2012a) Economic assessment of climate adaptation options for urban drainage design in Odense, Denmark. Water Sci Technol 66:1812-1820

Zhou Q, Mikkelsen PS, Halsnæs K, Arnbjerg-Nielsen K (2012b) Framework for economic pluvial flood risk assessment considering climate change effects and adaptation benefits. J Hydrol (Amst) 414-415:539-549

Proofs received from author(s): May 31, 2015 